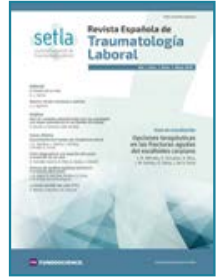

Revista Española de Traumatología Laboral

Vol. 1. Fasc. 1. Núm. 1. Mayo 2018

ISSN: 2605-0579 (impreso)

\title{
EDITORIAL
}

\section{La ilusión de un reto}

\section{The illusion of a challenge}

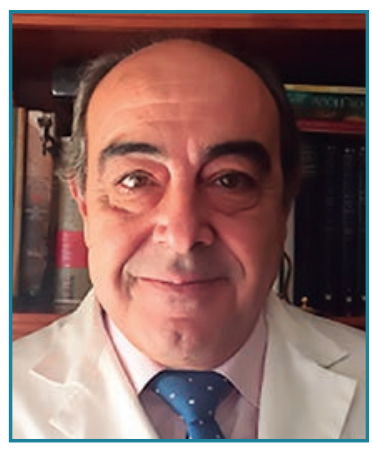

Ángel Luis García Berlinches Presidente de SETLA
Estimados socios de SETLA:

- engo el enorme privilegio y la satisfacción de presentaros el primer número de la Revista Española de Traumatología Laboral (RETLA) que hoy tenéis en vuestras manos, que nace como seña de identidad de nuestra sociedad y con vocación de permanecer mucho tiempo con nosotros.

El nacimiento de una revista es siempre un desafío intelectual, científico, financiero y desde luego un gran reto. Desafío, porque siendo conscientes del gran número y la calidad de las revistas médicas que existen, pensamos que existe un lugar para una nueva revista en el paisaje científico actual, dedicada a la divulgación, la enseñanza, el estudio, la investigación y la práctica de todos los aspectos relacionados con la Traumatología Laboral en su más amplia concepción, englobando todas aquellas áreas del conocimiento que tienen cabida en el prolijo campo de la asistencia sanitaria de los trabajadores, lo que significa que será una revista de contenido multidisciplinar, como lo es el ejercicio de nuestra profesión en el entorno laboral, tratando de dar respuesta y opinión a incertidumbres, lagunas y/o retos de carácter científico que nos abruman en el día a día de nuestro ejercicio profesional.

Y sin duda que se trata de un reto, porque es mucho el esfuerzo que conlleva editar una revista, no solo financiero, que también, sino especialmente en horas de trabajo de autores, editores, colaboradores, administrativos y un sinfín de profesionales que, quitando horas a su descanso, ocio, familia, etc., van a dedicarse -ya lo han hecho- con pasión a hacer realidad este sueño que desde hace tiempo teníamos en SETLA. A todos ellos mi reconocimiento y gratitud, que estoy convencido representa el sentimiento de todos los socios.

FS $\odot 2018$ Sociedad Española de Traumatología Laboral. Publicado por Imaidea Interactiva en FONDOSCIENCE ${ }^{\circledR}$ (www.fondoscience.com) Este es un artículo Open Access bajo la licencia CC BY-NC-ND (www.creativecommons.org/licenses/by-nc-nd/4.0/). 
Y va a ser una revista en papel. Ahora es cuando el reto se hace épico y muchos considerarán que hemos perdido la cabeza. ¿Quién apuesta por una revista impresa en estos tiempos en que la mayor parte de las revistas científicas de gran tradición han migrado sus ediciones en papel a la nube? Y, sin embargo, no sin debate en la Junta Directiva, nosotros creemos que, a pesar de las muchas ventajas que pueda tener la edición electrónica, a la que no vamos a renunciar, pues va a existir una versión digital de la revista, aún existen y se sabe apreciar por parte de muchos lectores, y no todos pertenecientes a generaciones de veteranos, el valor añadido de tener en las manos una publicación en papel, con su característico olor a tinta, con imágenes de calidad, de buena maquetación, facilidad de lectura, de estudio y posibilidad de, artículo en mano, discutir "cara a cara" con otro colega sobre su último editorial. No se trata de estar en contra de las nuevas herramientas o tecnologías, que somos conscientes de lo mucho que han aportado y aportarán al devenir científico de nuestra especialidad, sino de no renunciar por ello al valor de lo tradicional.

La revista tiene carácter semestral, por lo que está previsto que salgan dos números al año, uno en primavera y otro en otoño, y su acceso será gratuito para los socios de SETLA. Y se contempla, en un futuro, el acceso al resto de los profesionales o interesados en alguna de sus publicaciones mediante una aportación que contribuya al sostenimiento de la revista.

Deseamos aprovechar este lanzamiento para invitar a todos los socios en particular y a la comunidad científica en general a contribuir en este nuevo espacio con artículos originales, comentarios, opiniones y cuantas colaboraciones consideren oportunas, lo que va a marcar la salud y prosperidad de este proyecto.

\section{Ángel Luis García Berlinches}

Presidente de SETLA 